\title{
EFFECT OF NATURAL FIBROUS PLASTER ON LATERAL RESISTANCE OF MORTARLESS INTERLOCKING WALL
}

\author{
Furqan Qamar ${ }^{1}$, Terrence \\ Thomas ${ }^{2}$ and Majid $\mathrm{Ali}^{3}$ \\ ${ }^{1}$ Corresponding Author. Research student, University of Warwick UK \\ Email: f.qamar@warwick.ac.uk \\ ${ }^{2}$ Engineering Dept. University of Warwick CV47AL UK \\ ${ }^{3}$ Associate Professor, Department of Civil Engineering, Capital University of Science \\ and Technology, \\ Islamabad Campus, Pakistan.
}

\begin{abstract}
Masonry structure subjected to lateral loads like earthquake present some inadequacies due to lack of its tensile strength, as reported in the literature. Strength evaluation of the masonry houses defined by modern standards are based on quantitative assessment. As a result, validated mechanical parameters should be made available on large scale for practical applications. Therefore, in this study $2200 \mathrm{~mm}$ high interlocked masonry walls mostly used in poor developing countries are experimentally tested. The research focus was to evaluate the mechanical and dynamic parameters like elastic stiffness, first crack load, toughness index and dynamic stiffness. Experimental work was concentrated on fibrous plastered walls. Non-plastered and fibrous-plastered masonry walls were compared using natural fibre (rice straw) and subjected to lateral load. 2\% rice straw by weight of cement was used. The factor of increase in failure loads over unplastered walls was found to be up to $250 \%$ for fibrous plastered walls.
\end{abstract}

Keywords: Interlocked masonry walls, fibrous plastered walls.

\section{INTRODUCTION}

Masonry is considered as one of the ancient construction materials that is still valuable for reduced construction cost and time. Different types of the masonry unit developed over the time from simple block to interlocking blocks leading to mortarless construction. The types of the blocks used in the mortarless construction in the world nowadays include Haenar system, Mecano system (Vargas 1988), Abang interlocking system, Putra Block (Thanoon et al. 2004), Bamba system, Tanzanian interlock brick (TIB) system (Kintingu 2009) etc. Most of the block is similar with conventional block unit except it consist of additional projections and recesses that provide interlocking mechanism for mortarless construction (Safiee,2011). The behaviour of masonry walls subjected to out-of-plane loading has been explored by different researchers in various 
aspects (Rodriguez et al. 1998; Baqi et al. 1999; Velazquez and Ehsani 2000). Main source of out-of-plane loading for masonry walls are considered as wind and earthquake. Experimental study of reinforced and unreinforced masonry walls subjected to these lateral loading was previously studied (Drysdale and Essawy 1988; Velazquez and Ehsani 2000, Uzoegbo 2001; Griffith et al. 2004, Safiee et al. 2011 and Sokairge et al. 2017). However, work on masonry interlocking walls under out-ofplane loading has rarely been considered. In one of the studies by Uzoegbo 2001, experimental work is carried out on mortarless wall due to lateral loading and also plastering of walls are considered. The result showed that addition of plaster effect the lateral load resistance of interlocked walls and it was found that load carrying capacity increased by $20 \%$. In another study by Safiee et al. 2011, Putra block system were used and the behaviour of masonry wall under lateral load was experimentally investigated. It was found that behaviour of the wall was primarily dominated by large lateral displacement and dry joint opening approximately at mid height of wall. It was also found that slenderness ratio and amount of pre-compressive load significantly affected the deflections and out-of-plane load carrying capacity of the wall. By increasing the pre-compressive stress level of the wall, the moment capacity of the wall increased linearly. However, the wall capacity decreased by increasing the slenderness of the walls. In another research work by Sokairge et al. 2017, dry stack interlocking masonry system was used and tested for out-of-plane loading. It was discussed that this system has some disadvantages like low bending capacity and also interlocking units had to settle down to balance uneven surfaces which could result in low strength and stiffness of the walls. Therefore, some other mechanism or methods are required to overcome these deficiencies. In this study, Tanzanian interlock brick (TIB) system was used to build the wall and was subjected to lateral load. To improve the lateral resistance of the interlocking wall, plastering was considered with the addition of natural fibres like rice straw. Unplastered interlocked wall was considered as a reference. The comparison of mechanical properties of fibrous plastered and unplastered wall was carried out and the contribution of rice straw within plaster was evaluated. Snap back test was also carried out to evaluate the damping ratio of fibrous plastered and unplastered wall. Post-earthquake surveys have shown that unreinforced masonry structure most of the time suffer out of plane local collapse mechanisms (Sorrentino 2008). In order to get reliable analysis, estimation of damping energy is crucial (Ali 2007). Therefore, in this study, damping ratio of fibrous plastered and unplastered wall were compared to evaluate the contribution of fibre within plastering of masonry walls.

\section{EXPERIMENTAL PROCEDURE}

\section{Mix Ratio}

For Tanzanian Interlocked Blocks (TIB), the mix design ratio for soil and cement was 1:12 and blocks were made by manually pressed machine. The compressive strength of blocks was tested and found to be $1.58 \pm 0.24$ (average of 3 No samples) for a single block. In order to find the compressive strength of 1:3 cement sand mortar $100 \mathrm{~mm} *$ $100 \mathrm{~mm}$ fibrous and non - fibrous cubes were prepared and tested for compressive strength and found to be $9 \pm 1.15$ and $19.3 \pm 5$ (average of 3 No Samples), respectively. The tensile strength for the plaster and blocks was assumed to be $0.1 *$ compressive strength with a Poisson's ratio of 0.15 . For plain plaster, the mix design for cement and sand was $1: 3$ with a water cement $(\mathrm{W} / \mathrm{C})$ ratio of 0.67 . The mix ratio for the fibrous 
plaster was kept same. Whereas, more water was required in fibrous plaster to make the mix workable. All materials were weighed by mass of cement and $2 \%$ fibres were added in fibrous plaster samples. Manual mixing procedure was used for preparing the plain and fibrous plaster. First, cement and sand were mixed and then water was added to make a workable mix. For fibrous plaster, first sand and cement were mixed together, then layer of fibres was spread over and finally water was added slowly to make a workable mix.

\section{Wall Preparation and Specification}

TIB blocks (Figure 1) of size $300 \mathrm{~mm} \times 150 \mathrm{~mm} \times 100 \mathrm{~mm}$ were used. To avoid the instability of wall, 1 block return/support $(300 \mathrm{~mm}$ ) was provided as shown in the Figure $1.900 \mathrm{~mm} \times 150 \mathrm{~mm} \times 2200 \mathrm{~mm}$ high wall for each case were built and tested under a lateral load. Two walls were employed in the experiments and coded as shown in Table $1.10 \mathrm{~mm}$ thick plastered were applied on the face of the wall.

Table 1: Sample specifications

\begin{tabular}{|l|l|l|}
\hline Specimen & Unplastered Wall & Fibrous Plastered Wall \\
\hline Symbol & A & B \\
\hline
\end{tabular}
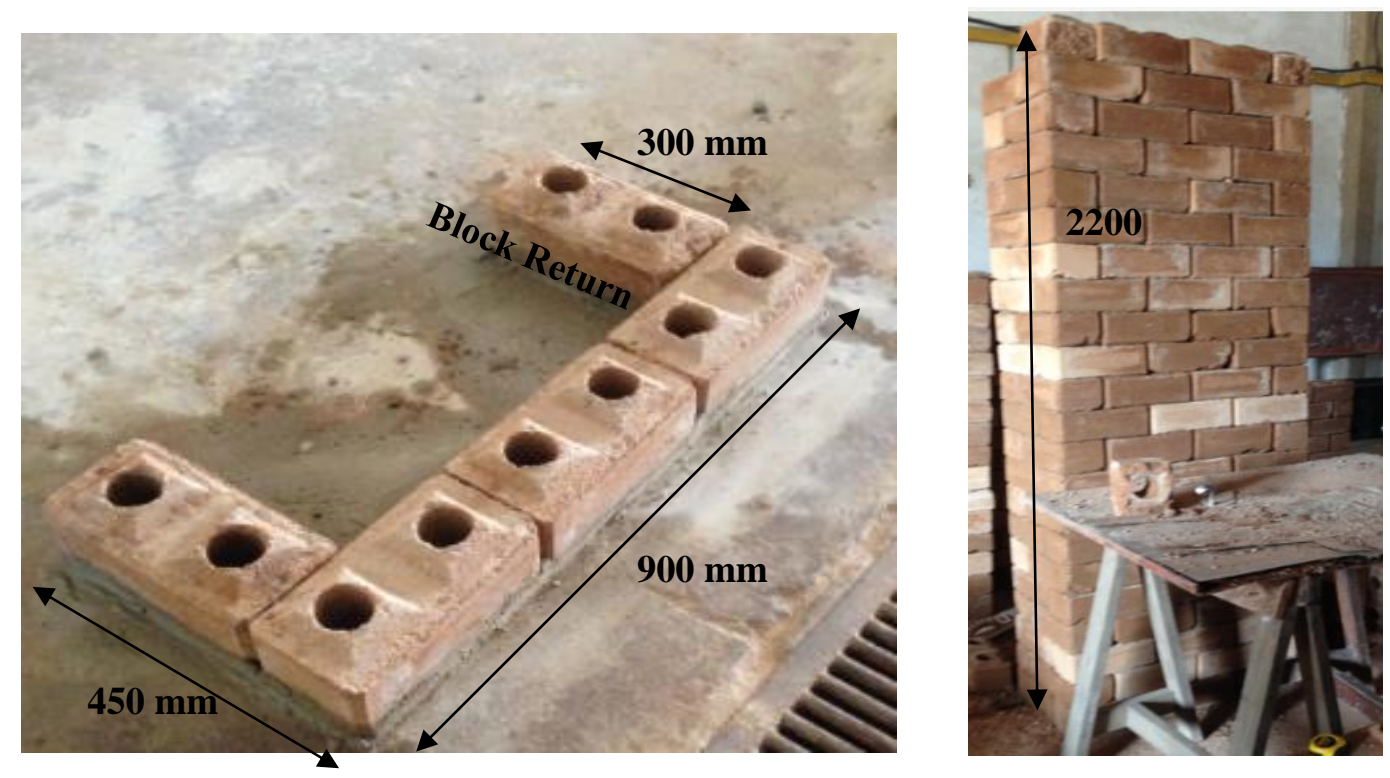

Figure 1: TIB wall construction

\section{Experimental Setup}

Figure $2 \mathrm{a} \& 2 \mathrm{~b}$ shows diagram representing the test setup. In small increments, lateral load was applied with the help of a bespoke pulley frame system at a height of 
$2200 \mathrm{~mm}$. Dial gauges are attached to the wall in the top course of block as shown in Figure 2a to obtain the displacement at the top of wall. Lateral load was applied with the help of steel wire which is passing over the pulley of the loading frame and attached to the wall with the help of steel plates. Loading was restricted initially to that, giving a displacement of 1 to $2 \mathrm{~mm}$. Loading was later increased, generally in steps of 40N, to find the start of cracking and collapse load
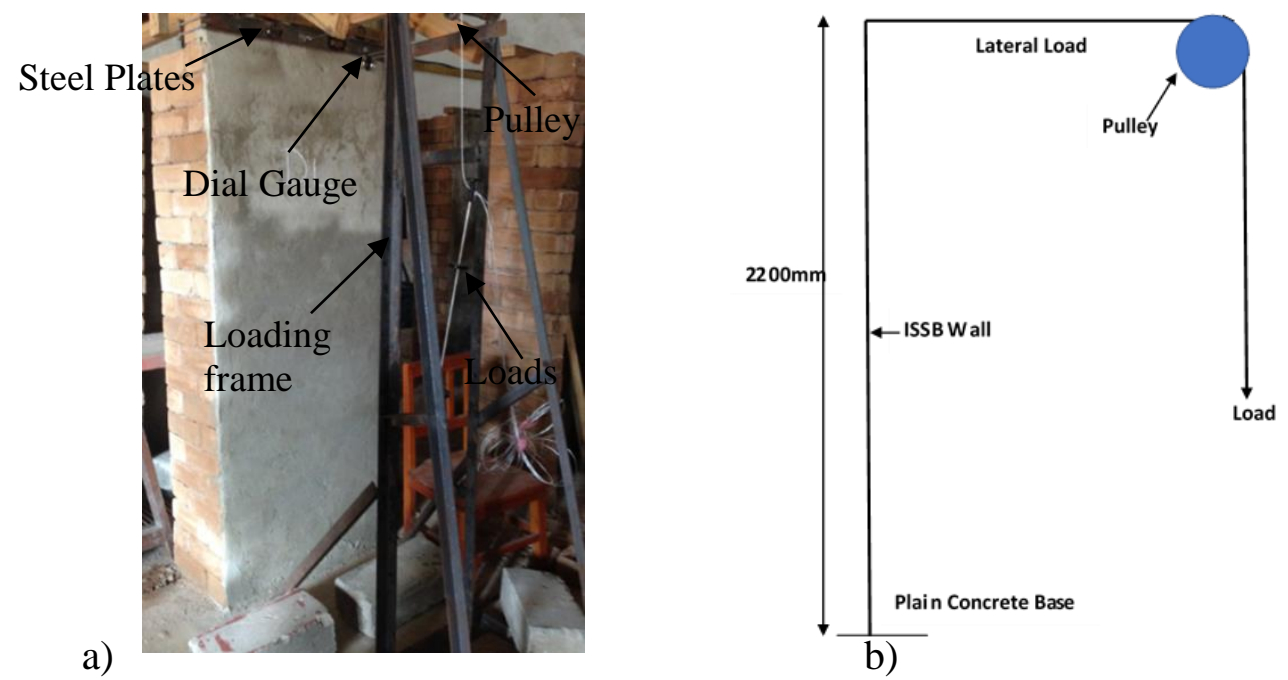

Figure 2: Test Setup a) Bespoke instrument for lateral load and b) Schematic representation

\section{RESULT AND ANALYSIS}

\section{Load - Displacement Graphs}

The result of each wall is detailed in the form of a load displacement plot as detailed in Figure 3. Figure 3 shows the load displacement plots for unplastered and fibrous plastered interlocking walls. It can be observed clear difference in the behaviour of both walls. The wall with fibrous plastered showed better stiffness as compared to unplastered interlocking wall. There was significant increase in the load carrying capacity of the fibrous plastered wall as compared to unplastered wall. The load increased to $1550 \mathrm{~N}$ for fibrous plastered wall as compared to $440 \mathrm{~N}$ for unplastered wall. Addition of fibrous plaster enhances the stiffness and the load carrying capacity. The displacement for unplastered wall was around $12 \mathrm{~mm}$ whereas fibrous plastered wall showed displacement of only $6 \mathrm{~mm}$.

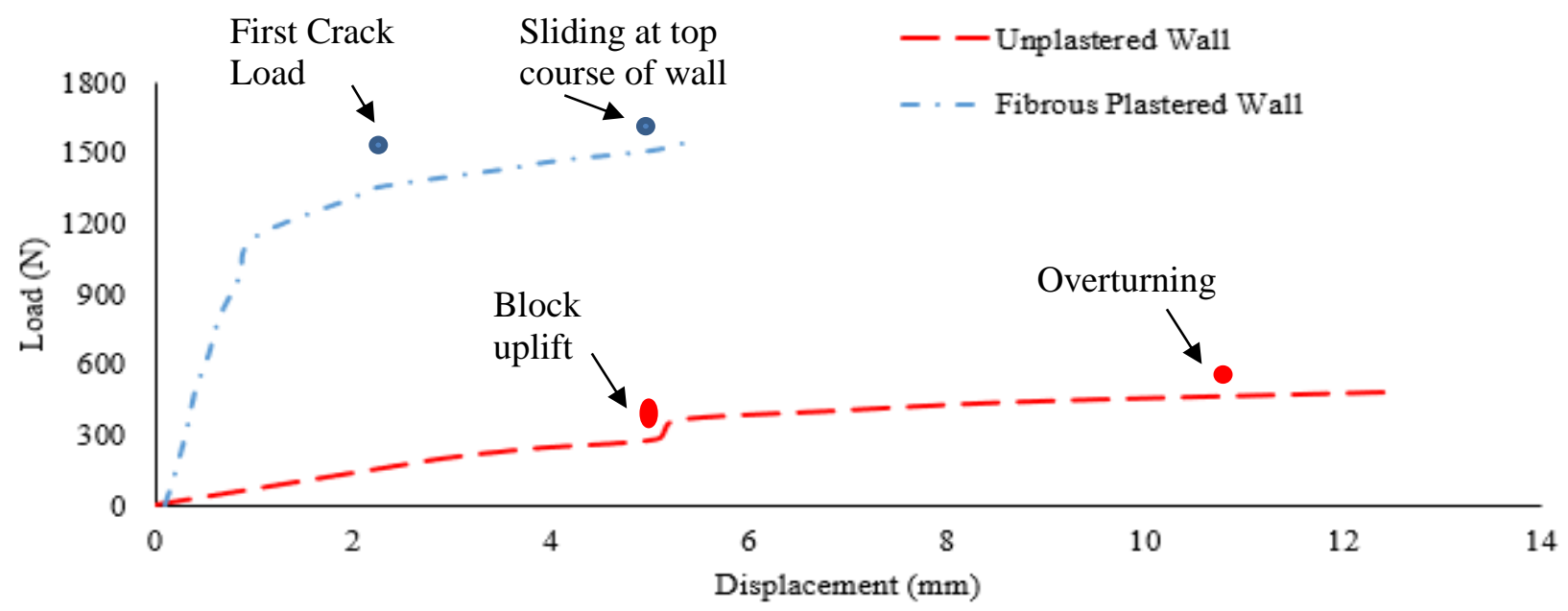


Figure 3: Load displacement curves of unplastered interlocking wall and fibrous plastered interlocking wall

Figure 4 explains the highest loads for the fibrous plastered and unplastered walls. The increase in peak load from unplastered to fibrous plastered wall is $440 \mathrm{~N}$ to $1550 \mathrm{~N}$. These are about 2.5 times increase in strength due to application of lateral load.

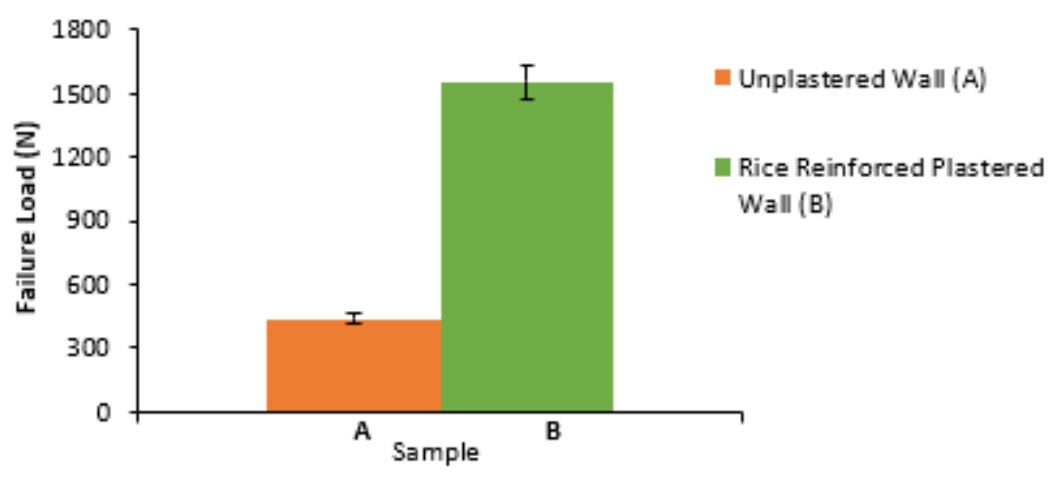

Figure 4: Failure load

\section{Contribution to Mechanical Properties}

Table 2 details the mechanical parameters of samples which include first crack load, first crack stiffness, pre- crack and post crack energy absorbed and toughness. First crack stiffness is calculated as the slope of load-displacement curve up to first crack load. Pre-crack and post crack energy absorbed are found by evaluating the areas up to first crack load and from first crack to ultimate load, respectively. Their summation is taken as total energy absorbed and the ratio of total energy to pre-crack energy is taken as toughness. It is evident from test data that the value for first crack stiffness for unplastered to fibrous plastered walling is increased from $49.7 \mathrm{~N} / \mathrm{mm}$ to $302 \mathrm{~N} / \mathrm{mm}$ which is about 5 times increase from unplastered to fibrous plastered wall. It should be noted that as the walls were constructed by using Tanzanian Interlocking blocks, there will be uplift of the blocks for unplastered wall instead of initiation of cracks which is considered as first crack load. Whereas, for plastered wall uplift will be restrained by the applied plaster and the crack will only be produced once it will exceed the tensile strength of plaster which will then become visible and will be considered as first crack load. The increase in pre-crack absorbed energy was evident from the test data and showed 94\% enhancement by the addition of fibrous plastered to the wall. The value of toughness for fibrous plastered wall showed a $132 \%$ increase from unplastered sample which represents ductile failure. The test result showed significant enhancement in the mechanical properties like elastic stiffness, pre and post crack energy absorbed and toughness by the addition of fibrous plaster to interlocked wall. 
Table 2: Mechanical properties of fibrous plastered and unplastered ISSB Wall

\begin{tabular}{|l|l|l|l|l|l|l|}
\hline Specimen & $\begin{array}{l}\text { First } \\
\text { crack load } \\
(\mathrm{N})\end{array}$ & $\begin{array}{l}\text { First } \\
\text { crack } \\
\text { stiffness } \\
(\mathrm{N} / \mathrm{mm})\end{array}$ & $\begin{array}{l}\text { Pre-crack } \\
\text { energy } \\
\text { absorbed } \\
(\mathrm{N}-\mathrm{mm})\end{array}$ & $\begin{array}{l}\text { Post crack } \\
\text { energy } \\
\text { absorbed } \\
(\mathrm{N}-\mathrm{mm})\end{array}$ & $\begin{array}{l}\text { Total } \\
\text { energy } \\
\text { absorbed }\end{array}$ & Toughness \\
$(\mathrm{N}-\mathrm{mm})$ & $(-)$ \\
\hline $\begin{array}{l}\text { Unplastered } \\
\text { Wall }\end{array}$ & 400 & 49.72 & 1477 & 0 & 2317 & 1 \\
\hline $\begin{array}{l}\text { Fibrous } \\
\begin{array}{l}\text { Plastered } \\
\text { Wall }\end{array}\end{array}$ & 1390 & 302 & 2871 & 3810 & 6681 & 2.32 \\
\hline
\end{tabular}

\section{Dynamic Stiffness}

Earthquakes are natural hazards which can lead to a catastrophic failure of the structures which can result in number of loss of human lives. It has been observed through number of studies that low-cost houses (non-engineered structures) including interlocked masonry suffered most from the earthquake disaster. Therefore, there is a great demand to understand the parameter of earthquake loading and develop techniques to increase the resistance of these structures. In this study one of the important parameters for earthquake resistance, dynamic stiffness was evaluated for unplastered and fibrous plastered walls. Dynamic stiffness is obtained by snap back test. In the snap back test, both walls pulled $10 \mathrm{~mm}$ and then released suddenly to allow them to vibrate freely. To avoid any crack formation in walls, smaller displaced position (i.e. $10 \mathrm{~mm}$ only) was chosen for snap back test. Dytran accelerometer was attached at the top of wall which was connected with the processor. The acceleration of the column by snap back test was recorded through accelerometer by using Lab View software and later data was imported in MATLAB to get the frequency of the system. Using this frequency and solving the equation 1, dynamic stiffness of the both samples were obtained and compared with lateral stiffness. The results of the dynamic stiffness of both samples are detailed in the Table 3 . The comparison of dynamic stiffness with lateral stiffness showed $28 \%$ difference for unplastered wall whereas the difference for the fibrous plastered wall was observed only $10 \%$. This has indicated that addition of fibrous plastered increased the lateral and dynamic stiffness to 5-6 times as compared to unplastered wall.

Table 3: Dynamic Stiffness of fibrous plastered and unplastered walls by snap back test

\begin{tabular}{|l|l|l|}
\hline Specimen & Unplastered Wall & Fibrous Plastered Wall \\
\hline Frequency $(\mathrm{Hz})$ & 1.27 & 1.306 \\
\hline Dynamic Stiffness $\mathrm{K}_{\mathrm{d}}(\mathrm{N} / \mathrm{mm})$ & 38 & 275 \\
\hline Lateral Stiffness $(\mathrm{N} / \mathrm{mm})$ & 49 & 302 \\
\hline Difference $(\%)$ & $28 \%$ & $10 \%$ \\
\hline
\end{tabular}

Note: $K d=\alpha F^{2} * 4 * \pi^{2} * m$; whereas $\mathrm{F}=$ Frequency $(\mathrm{Hz}) ; \mathrm{K}_{\mathrm{d}}=$ Dynamic Stiffness $(\mathrm{N} / \mathrm{mm}) ; \mathrm{m}=$ Mass $(\mathrm{kg})$ and $\alpha=$ dynamic factor 1 for unplastered wall and 6.5 for fibrous plastered wall. 


\section{CONCLUSIONS}

Experimental work was carried out to evaluate the improvement in mechanical parameters by the addition of natural fibre rice straw in the plaster of TIB wall. Each wall was tested under lateral loading and only one test was performed. Dynamic stiffness was also evaluated using snap-back test for both type of walls. The conclusions are as follows: In each case a fibre plastered TIB wall is compared to an unplastered wall.

1 Addition of natural fibre rice straw within the plaster applied to TIB wall increases lateral first crack stiffness by $500 \%$.

2 The failure load is increased by $250 \%$.

3 The pre-crack absorbed energy is increased to $94 \%$.

4 Dynamic stiffness is increased to $600 \%$, whereas lateral stiffness increase was $500 \%$

The above aspects can perform a major role in addressing the inadequate lateral resistance of interlocked walling system for low cost housing. This contribution of cheap locally available natural fibres can help in development of more robust and economical housing for rural areas.

\section{ACKNOWLEDGEMENTS}

The authors would like to thank all people and organizations including National housing and Building Research Agency (NHBRA), who helped them throughout this research work. The careful review and valuable recommendations by the anonymous reviewers are appreciatively acknowledged.

\section{REFERENCES}

Ali, Q. \& Naeem, A. (2007) Seismic resistance evaluation of unreinforced masonry buildings. Journal of Earthquake Engineering, 11 (2): 133-146.

Baqi, A., Bhandari, N. M. \& Trikha, D. N. (1999) Experimental study of prestressed masonry flexural elements. Journal of Structural Engineering, 125 (3): 245-254.

Basoenondo, E. A., Giles, R. S., Thambiratnam, D. P. \& Purnomo, H. (2001) Response of Unreinforced Brick Masonry Wall Structures to Lateral Loads. In: Zingoni, A., ed. Structural Engineering, Mechanics and Computation. Oxford: Elsevier Science: 419-425.

Drysdale Robert, G. \& Essawy Ahmed, S. (1988) Out-of-Plane Bending of Concrete Block Walls. Journal of Structural Engineering, 114 (1): 121-133.

Griffith Michael, C., Lam Nelson, T. K., Wilson John, L. \& Doherty, K. (2004) Experimental Investigation of Unreinforced Brick Masonry Walls in Flexure. Journal 
of Structural Engineering, 130 (3): 423-432.

Kintingu, S. H. (2009). Design of interlocking bricks for enhanced wall construction, flexibility, alignment accuracy and load bearing. PhD Thesis .

Rodriguez, R., Hamid, A. A. \& Larralde, J. (1998) Flexural behavior of post-tensioned concrete masonry walls subjected to out-of-plane loads. ACI Structural Journal, 95 (1): $61-70$

Safiee, N., Jaafar, M., Alwathaf, A., Noorzaei, J. \& Abdulkadir, M. (2011) Structural behavior of mortarless interlocking load bearing hollow block wall panel under outof-plane loading. Advances in Structural Engineering, 14 (6): 1185-1196.

Sokairge, H., Rashad, A. \& Elshafie, H. (2017) Behavior of post-tensioned dry-stack interlocking masonry walls under out of plane loading. Construction and Building Materials, 133 348-357.

Sorrentino, L., Masiani, R., Benedetti, S., Santini, A. \& Moraci, N. (2008) Experimental estimation of energy damping during free rocking of unreinforced masonry walls. First results. 2008 Seismic Engineering Conference Commemorating the 1908 Messina and Reggio Calabria Earthquake, Pts 1 and 2, 1020 1888-1895.

Thanoon, W. A., Jaafar, M. S., Kadir, M. R. A., Ali, A. A. A., Trikha, D. N. \& Najm, A. M. S. (2004) Development of an innovative interlocking load bearing hollow block system in Malaysia. Construction and Building Materials, 18 (6): 445-454.

Uzoegbo, H. C. (2001) - Lateral Loading Tests on Dry-Stack Interlocking Block Walls. In: Zingoni, A., ed. Structural Engineering, Mechanics and Computation. Oxford: Elsevier Science: 427-436.

Vargas, H. G. (1988) MORTARLESS MASONRY: THE MECANO SYSTEM. International Journal for Housing Science and Its Applications, 12 (2): 145-157.

Velazquez-Dimas, J. I. \& Ehsani, M. R. (2000) Modeling out-of-plane behavior of URM walls retrofitted with fiber composites. Journal of Composites for Construction, 4 (4): 172-180. 